\title{
煤和沉积岩中各种形式硫的提取和同位 素样品制备
}

\author{
储雪蕾 赵 瑞 䠞文秀 \\ (中国科学院地质研究所, 北京 100029) \\ 雷加锦唐跃刚 \\ （中国矿业大学北京研究生部, 北京 100083）
}

\section{关键词煤、硫同位素、沉积岩}

煤或沉积岩的硫同位素研究不仅可以提供硫的来源, 也可以提供沉积环境、成煤或成岩作 用等方面的信息. 很多煤和富含有机质的沉积岩(例如黑色页岩)硫含量较高, 且以黄铁矿、单 硫化物、硫酸盐和有机硫等多种形式硫出现. 同一样品不同形式硫的同位素组成不同, 可差 $30 \%$ ，所以分析每种硫(而不是总硫)的同位素组成实际上更有意义.

一般通过化学方法来分离和提取岩石中各种硫. 关键是寻找一种适宜的还原剂能够还原 黄铁矿而不还原或破坏硫酸盐和有机硫, 从而可以分离黄铁矿与硫酸盐和有机硫. 目前, 煤和 页岩的各种硫同位素样品制备主要采用氢化锂铝作还原剂 ${ }^{[1-3]}$. 由于氢化锂铝遇水会爆炸, 实 验只能在氧杂环戊烷介质中进行, 还要用冰浴来降低反应速度. 这种方法不易操作, 成本高, 缺点明显.

Canfield 等人用 $\mathrm{CrCl}_{2}$ 盐酸溶液作还原剂来测定沉积物和页岩中还原态无机硫总若 ${ }^{[4]}$. 他们的实验表明 $\mathrm{Cr}^{2+}$ 离子能够定量地还原黄铁矿（回收率为 $95.9 \%$ ) 而基本不还原或破坏硫 酸盐和各种有机硫。在他们工作的基础上, 本文提出一个提取和制备煤和沉积岩中各种硫同 位素样品的新流程, 并结合具体煤样品的各种硫同位素分析结果进行讨论.

\section{1 分离流程和装置}

煤和沉积岩中各种硫的分离流程如图 1 所示,具体步骤如下:

\section{1 块状黄铁矿硫的分离}

尽量手选样品中肉眼可见的黄铁矿。选后的样品磨至 $<120$ 目, 进人下一步分离。

\section{2 单硫化物的分离}

单硫化物溶于酸, 为酸可溶硫化物. 加人 $4.8 \mathrm{~mol} / \mathrm{L}$ 的 $\mathrm{HCl}$ 劣沸, 使这部分硫以 $\mathrm{H}_{2} \mathrm{~S}$ 的 形式放出, 从而使它与黄铁矿、硫酸盐和有机硫等分开.

实验装置如图 2 所示. 水冷凝器之上是两个串接的球形漏斗. 上面为分液漏斗, 带活塞. 下面漏斗的侧面有两个开口, 一个供通入气体用,一个供排出气体用(它实际在磨口处, 不与漏 斗内通) ; 漏斗下面的玻璃管细长, 可达烧瓶底部. 漏斗之间以及漏斗、冷凝器和烧瓶之间都是 通过玻璃磨口连接. 


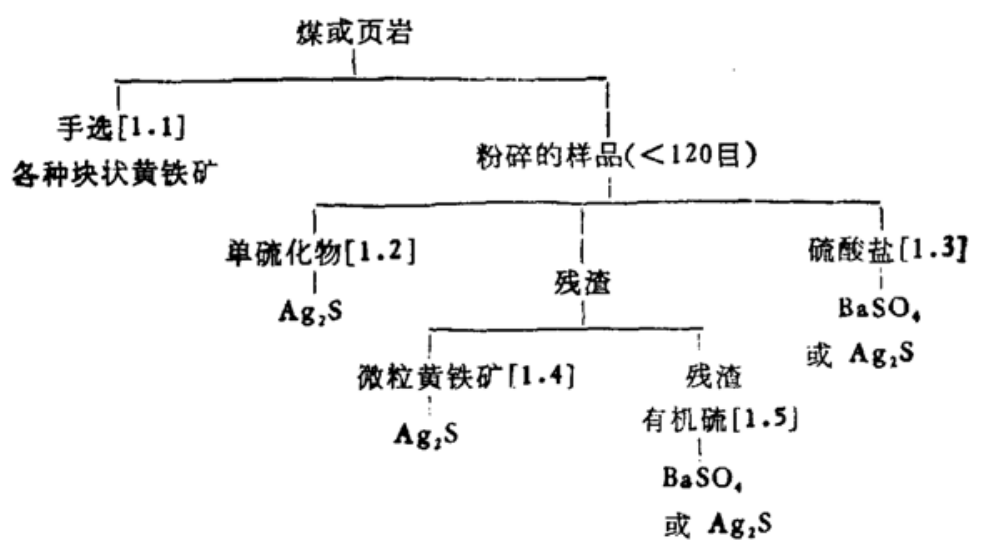

图 1 煤和沉积岩中各种形式硫的分离流程和硫同位素样品制备

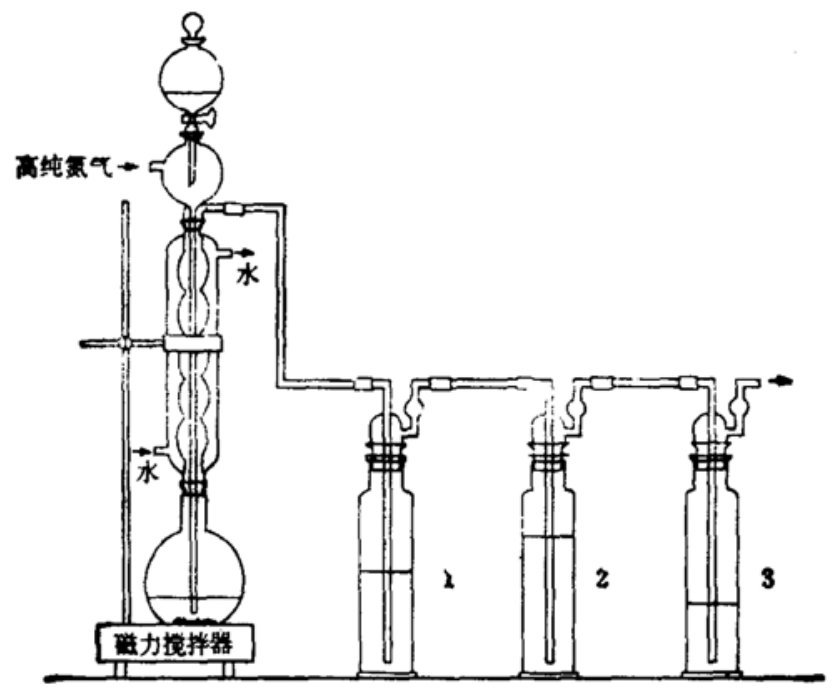

图 2 硫提取的主要实验装置图

$$
1,2,3 \text { 为洗气瓶 }
$$

称适量粉末样品, 加人烧瓶底部. 在分液漏斗中加人 $4.8 \mathrm{~mol} / \mathrm{L}$ 的 $\mathrm{HCl}$ 溶液 (按每克样 $10 \mathrm{ml}$ 加), 并在第 1,2 和 3 号洗气瓶中分别加人 $150 \mathrm{ml}$ 蒸馏水、 $250 \mathrm{ml}$ 和 $100 \mathrm{ml}$ 醋酸镉溶液, 按图 2 接好. 醋酸镉溶液是按每升 $3.5 \mathrm{~mol} / \mathrm{L}$ 醋酸溶液溶解 $25 \mathrm{~g}$ 醋酸镉来配制. 打开高纯氮 钢瓶, 用氮气排除装置内的空气, 并检查系统是否漏气. 若不漏气, 停氮气并打开分液漏斗活 塞, 让盐酸全部滴人烧瓶. 然后恢复氮气, 调整氮气流量 $(2-3$ 个气泡 $/ \mathrm{s})$. 再接通冷却水, 打 开磁力搅拌器, 并开始加热, 2 号洗气瓶应出现黄色 CdS 沉淀. 直到沸滕厈 $1-2 \mathrm{~h}$, 不再有新 沉淀生成为止.

在有沉淀的洗气瓶中滴人 $2 \%$ 的硝酸银溶液,使沉淀完全转变为黑色 $\mathrm{Ag}_{2} \mathrm{~S}$ 沉淀. 过滤 或离心分离出沉淀, 用 $5 \%$ 氨水洗一遍, 再用蒸馏水洗数遍, 最后在 $95^{\circ} \mathrm{C}$ 的烘箱中烘干.

\section{3 硫酸盐的分离}

烧瓶中的残渣和溶液通过过滤分开. 用 $35 \mathrm{ml}$ 的 $0.5 \mathrm{~mol} / \mathrm{L} \mathrm{HCl}$ 淋洗残渣, 将滤液收集起 来. 最后用蒸馏水淋洗残渣数遍, 直至流出的淋洗液 $\mathrm{pH}$ 值达到 4 . 洗净的残潈在 $60^{\circ} \mathrm{C}$ 的烘 箱中烘干,供进一步分离使用。

在收集的滤液中加人 $10 \mathrm{ml}$ 饱和的澳水業沸, 直至溶液变成无色. 滴人几滴甲基橙, 溶液. 
应星红色. 若为橙色, 可滴人盐酸, 直至溶液星红色为止. 在煮沸的溶液中加人 $15 \mathrm{ml}$ 的 $10 \%$ $\mathrm{BaCl}_{2}$ 溶液,会有白色 $\mathrm{BaSO}_{4}$ 沉淀生成. 经过几次升温和冷却,将溶液放至过夜. 次日过滤沉 腚, 并用热蒸馏水淋洗沉淀数遍. 沉淀与滤纸一起放在瓷坩埚中碳化, 然后在马福炉中灰化. $\left(950^{\circ} \mathrm{C}\right.$ 下 $\left.2 \mathrm{~h}\right)$, 就得到纯净的 $\mathrm{BaSO}_{4}$, 也可再把 $\mathrm{BaSO}_{4}$ 转化为 $\mathrm{Ag}_{2} \mathrm{~S}^{[1-3]}$.

\section{4 黄铁矿的分离}

$\mathrm{CrCl}_{2}$ 溶液的配制方法与 Canfield 等人的方法 ${ }^{[4]}$ 略有不同. 按 $133 \mathrm{~g}$ 的 $\mathrm{CrCl}_{3} \cdot 6 \mathrm{H}_{2} \mathrm{O}$ 溶 解于 $50 \mathrm{cml}$ 的 $0.5 \mathrm{~mol} / \mathrm{L} \mathrm{HCl}$ 溶液的比例先配制 $\mathrm{CrCl}_{3}$ (绿色)溶液, 只是采用带有玻璃磨 口的试剂瓶来配制和保存 $\mathrm{CrCl}_{2}$ (蓝色)溶液。在瓶中加入 $2 \%$ 硝酸永处理后的锌粒和 $\mathrm{CrCl}_{3}$ 溶液, 摇晃并放置过夜就得到完全蓝色的 $\mathrm{CrCl}_{2}$ 溶液. 我们方法的好处是 $\mathrm{Cr}^{2+}$ 不会被氧。 化.

具体操作与单硫化物分离相同。称适量的烘干的残渣倒人烧瓶底部,再加人 $10 \mathrm{ml}$ 的无水 乙醇. 分液漏斗中加人 $20 \mathrm{ml}$ 浓盐酸和 $40 \mathrm{ml}$ 的 $\mathrm{CrCl}_{2}$ 溶液 (足以还原几百毫克的黄铁矿). 反应大约需 2-4h. 最后, 可得纯净的 $\mathrm{Ag}_{2} \mathrm{~S}$ 和提取后的残渣.

\section{5 有机硫的提取}

将残渣与艾士卡试剂 $\left(\mathrm{MgO}: \mathrm{Na}_{2} \mathrm{CO}_{3}-3: 2\right.$, 重量)按重量比 $1: 3$ 混合加人瓷坩埚中，在 $800^{\circ} \mathrm{C}$ 的马福妒中, 熔样 $2 \mathrm{~h}$. 以后的操作类似硫酸盐的分离, 最后得到纯净的 $\mathrm{BaSO}$ 、或 $\mathrm{Ag}_{2} \mathrm{~S}$.

\section{2 实验结果和讨论}

按上述流程我们完成了四个费州晚二叠系煤样品的各种硫的分离和同位素分析. 采样地 点、煤类型和各种硫的同位素分析结果如表 1 所示. 表中还给出江苏省煤研所的硫化学分析 结果. 他们未列单硫化物项, 按他们的分析流程有机硫项含单硫化物的硫. 煤中单硫化物含 量一般较低, 我们分离时也只发现 GD-1 样品略微有点黄色沉淀, 其余均没有. 这四个样品 的黄铁矿都是用化学方法分离的, 转化为 $\mathrm{Ag}_{2} \mathrm{~S}$. 它们的硫酸盐和有机硫均转化成为 $\mathrm{BaSO}_{1}$, 采用直接热解法以制备 $\mathrm{SO}_{2}$. 硫同位素分析是在国产 $\mathrm{ZhT}-03$ 质谱计上完成, 分析精度为 $\pm 0.2(a) \%$.

表 1 四个贵州省晚二叠煤样品中硫的化学分析结果和硫同位案分析结果”)

\begin{tabular}{|c|c|c|c|c|c|c|c|c|c|c|}
\hline \multirow{2}{*}{ 编号 } & \multirow{2}{*}{ 类型 } & \multirow{2}{*}{ 地点 } & \multicolumn{3}{|c|}{ 各种硫的化学含量 (\%) } & \multirow{2}{*}{ 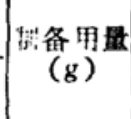 } & \multicolumn{4}{|c|}{ 各种硫的 $\delta^{34} S$ 值 $(\% 0)$} \\
\hline & & & 黄铁矿 & 硫酸搵 & 有机艈 & & 黄铁矿 & 单硫化物 & 硫酸盐 & 有机硫 \\
\hline GD-1 & 焦 媒 & 贵定 & 1.14 & 0.02 & 8 & 4 & -28.2 & - & -22.7 & -7.4 \\
\hline GD-2J & 焦 煤 & 贵定 & 1.07 & 0.03 & 6 & 2 & -30.3 & - & -59.5 & -7.4 \\
\hline LD-1 & 肥焦桨 & 六枝 & 3 & - & 1.45 & 4 & -9.4 & - & -8.8 & -4.4 \\
\hline PS-SB & 肥 煤 & 盘县 & 0.9 & - & 0.6 & 6 & -9.3 & - & - & -12.8 \\
\hline
\end{tabular}

2）表中一为含显低,无法分析.

根据表 1 的硫同位素数据, 得出以下初步结论:（1)煤中有机硫与黄铁矿硫的同位素组成 明显不同,一般有机硫比黄铁矿更富集 ${ }^{34} \mathrm{~S}$; (2) 煤中硫酸盐的硫与黄铁矿有关, 可能是黄铁 矿氧化的产物;（3）贵定与六盘水地区的煤同产于晚二叠系地层中但硫同位素特征却明显不 
同，贵定煤的黄铁矿比六盘水更铞 ${ }^{34} \mathrm{~S}$. 结合煤田地质的深入研究将另文给出.

致请感谢李任伟研究员、霍卫国和姚御元高级工程师给予的支持和帮助.

\section{胠考文献}

[1] Price, T. F., Shieh, Y. N., Econ. Geol., 1979, 74:1445 -1461.

[2] Westgate, L. M., Anderson, T. F., Anal. Chem.. 1982. 54:2136-2139.

[3] 傅家谟等主编,煤成烃地球化学,科学出版祈, 1992,89-113.

[4] Canfield, D. E. et al., Chem. Geol., 1986, 54:149-155.

[5]储篦管, 地质科学, 1993,28: 187-190. 